\title{
Aspiration Pneumonia in Older Adults
}

\author{
Alexander Makhnevich, MD ${ }^{1,2 *}$; Kenneth H Feldhamer, MD ${ }^{1,2}$; Charles L Kast, MD 1,2; Liron Sinvani, MD ${ }^{1,2}$ \\ ${ }^{1}$ Northwell Health, Manhasset, New York; ${ }^{2}$ Donald and Barbara Zucker School of Medicine at Hofstra/Northwell, Hempstead, New York.
}

Aspiration pneumonia refers to an infection of the lung parenchyma in an individual that has inhaled a bolus of endogenous flora that overwhelms the natural defenses of the respiratory system. While there are not universally agreed upon criteria, the diagnosis can be made in patients with the appropriate risk factors and clinical scenario, in addition to a radiographic or an ultrasonographic image of pneumonia in the typical dependent lung segment. Treatment options for aspiration pneumonia vary based on the site of acquisition (community-acquired aspiration pneumonia [CAAP] versus healthcare-associated aspiration pneumonia [HCAAP]), the risk for multidrug-resistant (MDR) organisms, and severity of illness. Hospitalized CAAP patients without severe illness and with no risk for MDR organisms or Pseudomonas aeruginosa (PA) can be treated with standard inpatient community-acquired pneumonia therapy covering anaerobes. Patients with
CAAP and either of the following - risk factors for MDR pathogens, septic shock, need for an intensive care unit (ICU) admission, or mechanical ventilation — can be considered for broader coverage against anaerobes, methicillin-resistant Staphylococcus aureus (MRSA), and PA. Severe aspiration pneumonia that originates in a long-term care facility or HCAAP with one or more risk factors for MDR organisms should be considered for similar treatment. HCAAP with one or more risk factors for MDR organisms or PA, plus septic shock, need for ICU admission or mechanical ventilation should receive double coverage for PA in addition to coverage for MRSA and anaerobes. Multiple gaps in current understanding and management of aspiration pneumonia require future research, with a particular focus on antibiotic stewardship. Journal of Hospital Medicine 2019;14:429-435. Published online first February 20, 2019. (C) 2019 Society of Hospital Medicine

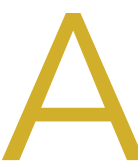

spiration pneumonia refers to an infection of the lung parenchyma in an individual who has inhaled a bolus of endogenous flora that overwhelms the natural defenses of the respiratory system. It primarily affects older adults with almost $80 \%$ of cases occurring in those 65 years and older. ${ }^{1}$ Compared with nonaspiration pneumonia, aspiration pneumonia (whether community acquired or healthcare associated) results in more ICU stays, mechanical ventilation, increased length of hospital stay, and higher mortality. ${ }^{2}$

The etiology of aspiration pneumonia comes from aspirated bacteria from the oropharynx or stomach. ${ }^{3}$ However, aspiration alone is a common occurrence and does not always lead to clinical pneumonia. Indeed, one study demonstrated that $45 \%$ of "normal subjects" aspirate in their sleep, ${ }^{4}$ illustrating that our bodies have evolved defense mechanisms to protect us from aspirated bacteria. Thus, it is only when these systems are overwhelmed, after compromise of both glottic closure and the cough reflex in addition to dysphagia, ${ }^{3}$ that an infection manifests.

\section{ASPIRATION PNEUMONITIS}

Aspiration pneumonitis refers to a significant inflammation of the lung parenchyma that results from inhalation of regurgitat-

\footnotetext{
*Corresponding Author: Alexander Makhnevich, MD; E-mail: amakhnev@ northwell.edu; Telephone: 516-562-2945; Twitter: @amakhnev1
}

Received: May 10, 2018; Revised: December 10, 2018;

Accepted: December 20, 2018

(C) 2019 Society of Hospital Medicine DOI 10.12788/jhm.3154 ed gastric contents. ${ }^{5}$ It can produce fever, cough, wheezing, shortness of breath, hypoxemia, leukocytosis, and a pulmonary infiltrate as well as lead to severe acute respiratory distress syndrome and even death. In the past, the use of antibiotics shortly after aspiration in patients who develop a fever, leukocytosis, or a pulmonary infiltrate was discouraged. ${ }^{5}$ Empiric antibiotics were recommended only for patients who aspirate gastric contents and who have conditions associated with colonization of gastric contents, such as small-bowel obstruction. ${ }^{5}$ Yet, it is difficult to distinguish aspiration pneumonitis from pneumo$n^{n}{ }^{6}$ and there are no randomized trials in older adults to help guide their management.

\section{PRESENTATION OF ASPIRATION PNEUMONIA}

Pneumonia in older adults can present in an atypical fashion. In one study of community-acquired pneumonia (CAP), the combination of cough, fever, and dyspnea is present in only $31 \%$ of patients, although separately, they are present in $67 \%$, $64 \%$, and $71 \%$ of patients, respectively. The same study also showed that delirium was present in $45 \%$ of patients with CAP? Nonrespiratory symptoms were present during the initial presentation of CAP in $55 \%$ of patients, with confusion in $42 \%$, and falls in $16 \%$ of cases. ${ }^{8}$ The same is true of aspiration pneumonia where altered mental status is seen in approximately $30 \%$ of community-acquired aspiration pneumonia (CAAP) patients and in $19 \%$ of continuing care facility patients with aspiration pneumonia. ${ }^{2}$ Another study that compared CAP, CAAP, and healthcare-associated aspiration pneumonia (HCAAP) showed that confusion is present in $5.1 \%, 12.7 \%$, and $18.6 \%$, respec- 
tively. ${ }^{9}$ The absence of fever in older adults is shown in studies where fever, defined as greater than or equal to $37.5^{\circ} \mathrm{C}$, is absent in $32 \%$ of the very old $\mathrm{d}^{10}$ and in $40 \%$ of patients 65 years or older when it was defined as greater than $37^{\circ} \mathrm{C} .{ }^{8}$ The inconsistencies regarding typical symptoms of pneumonia in the older adult population are also confirmed in nursing home residents. ${ }^{11}$ Ultimately, it is important to remember that any infection in older adults, especially in those residing in longterm care facilities, may present with subtle findings such as an acute change in cognitive and functional status. ${ }^{12}$

\section{Risk Factors for Aspiration Pneumonia}

Risk factors for aspiration pneumonia, while not universally agreed upon, are important to recognize as they increase the probability of the diagnosis when present. A 2011 systematic review identified age, male gender, lung disease, dysphagia, and diabetes mellitus (level 2a), as well as severe dementia, angiotensin l-converting enzyme deletion/deletion genotype, and poor oral health (level 2b) as risk factors. ${ }^{13}$ In 2016, a panel of experts reached a consensus (modified Delphi Method) on the following risk factors for the diagnosis of aspiration pneumonia in nursing home residents: history of dysphagia, choking incident, tube feeding, neurologic disease, and cognitive impairment. The presence of one or more of these risk factors in the appropriate clinical setting may suggest a diagnosis of aspiration pneumonia. ${ }^{14}$

\section{Radiographic/Ultrasonographic Imaging}

In the appropriate scenario, the diagnosis of aspiration pneumonia is supported with an image representative of pneumonia. The pulmonary segment involved in aspiration pneumonia depends on the position of the patient during the aspiration event. If the aspiration event occurs while the patient is in the recumbent position, development of pneumonia is more common in the posterior segments of the upper lobes and the apical segments of the lower lobes; whereas if it occurs while the patient is in an upright position, the location changes to the basal segments of the lower lobes. ${ }^{3}$

Overall, the sensitivity of a chest X-ray to diagnose pneumonia ranges between $32 \%-77.7 \%, 15-17$ suggesting that a significant proportion of patients suspected of having pneumonia in past research studies, may have been misdiagnosed. Studies using lung ultrasound to identify pneumonia demonstrate a higher sensitivity, but additional research is needed to validate these findings. ${ }^{17-19}$ Noncontrast CT scans of the chest remain the reference standard for diagnosing pneumonia and currently tend to have the largest impact on diagnosis and subsequent treatment decisions. ${ }^{15,16,20,21}$ As a result, if radiation exposure risks are not a concern for the patient, we recommend utilizing noncontrast CT imaging whenever the diagnosis is in doubt until future research elucidates the most appropriate approach to imaging.

\section{Diagnosis}

Diagnosing aspiration pneumonia is difficult, in part because there is no universal definition or set of diagnostic criteria. The diagnosis of aspiration pneumonia is supported by the fulfillment of three criteria. First, appropriate risk factors for aspiration, as documented above, should be present. Second, there should be evidence of clinical signs and symptoms of pneumonia (typical or atypical). Third, radiographic representation of pneumonia in a dependent pulmonary segment confirms the diagnosis. Once these criteria are met, it is important to distinguish between CAAP and HCAAP with particular attention to risk factors for multidrug-resistant (MDR) organisms and Pseudomonas aeruginosa (PA).

\section{MICROBIOLOGY}

Many studies have tried to determine the exact bacterial etiology of aspiration pneumonia as documented in the Table.

Even when an ideal method is used to obtain a good sample, however, the results are limited by other variables in the study. For example, in studies that use protected brush specimens and protected bronchoalveolar lavage to acquire samples for culture, many patients received antibiotics prior to sampling, and the studies are small (Table). Although anaerobes have traditionally been implicated in aspiration pneumonia, only El-Solh et al. ${ }^{22}$ were able to culture a significant proportion of anaerobes. The study, however, was limited to institutionalized older adults requiring mechanical ventilation and it did not require the typical radiographic location for aspiration pneumonia. Even under the best circumstances, it is difficult to determine causality because the antibiotics used to treat these cases of aspiration pneumonia cover a broad range of organisms. Based on the studies in the Table, causative organisms may include Streptococcus pneumoniae, Haemophilus influenzae, Staphylococcus aureus, and gram-negative rods in addition to traditional organisms classically thought to cause aspiration pneumonia-anaerobes. Microbiologic etiology, however, may also be insinuated from the studies discussed in the therapeutic strategies section below as some include antibiotics with limited antimicrobial activity.

\section{Therapeutic Strategies}

The management of aspiration pneumonia has evolved significantly since it was first studied in the 1970s because of the development of antibiotic resistance patterns, newer antibiotics, and increasing information on the diversity of pathogens involved in each subset of aspiration syndromes. The antimicrobial treatment of aspiration pneumonia was classically directed against anaerobic pathogens; treatment of these infections, however, was extrapolated from studies of pulmonary abscesses and other anaerobic pulmonary infections.

A randomized controlled trial in the mid-1980s comparing penicillin and clindamycin demonstrated a significantly improved cure rate in the clindamycin group. ${ }^{23}$ A follow-up study in 1990 implicated a significant number of penicillin-resistant Bacteroides infections - the majority of these infections were subsequently reclassified as Prevotella melaninogenica-as the cause for high rates of penicillin resistance in lung abscesses and necrotizing pneumonias, further supporting 
TABLE. Determining Bacterial Etiology of Aspiration Pneumonia

\begin{tabular}{|c|c|c|c|}
\hline Study & $\begin{array}{l}\text { Radiographic Criteria } \\
\text { for Diagnosis }\end{array}$ & Microbiology & Limitations \\
\hline $\begin{array}{l}\text { Mier et al. }{ }^{49} \text { (1993) } \\
\text { Prospective }\end{array}$ & Alveolar opacity & $\begin{array}{l}\text { Blood culture: } \\
\text { Streptococcus pneumoniae (1 patient) } \\
\text { Staphylococcus aureus (1 patient) } \\
\text { Protected brush specimen isolates: } \\
\text { Staphylococcus aureus 22\% } \\
\text { Streptococcus pneumonia 15\% } \\
\text { Pseudomonas aeruginosa 11\% } \\
\text { Haemophilus influenzae 7.4\% } \\
\text { Escherichia coli 7.4\% } \\
\text { Proteus mirabilis 7.4\% } \\
\text { Streptococcus sp. 7.4\% } \\
\text { Klebsiella pneumoniae 3.7\% } \\
\text { Enterobacter cloacae 3.7\% } \\
\text { Serratia marcescens 3.7\% } \\
\text { Streptococcus viridans 3.7\% } \\
\text { Morganella morgannii 3.7\% } \\
\text { Candida albicans 3.7\% }\end{array}$ & $\begin{array}{l}\text { Small sample size; only ICU patientsa; alveolar opacity did not have to } \\
\text { be in a dependent lobe; antibiotics were administered before protected } \\
\text { brush specimen (PBS) cultures were obtained }\end{array}$ \\
\hline $\begin{array}{l}\text { Marik et al. } .^{50} \text { (1999) } \\
\text { Prospective }\end{array}$ & Alveolar infiltrate & $\begin{array}{l}\text { Protected specimen brush sampling and mini-bronchoalveolar lavage } \\
\text { isolates: } \\
\text { Enterobacter spp 17.6\% } \\
\text { Streptococcus pneumoniae } 11.7 \% \\
\text { Methicillin-sensitive Staphylococcus aureus (MSSA) 11.7\% } \\
\text { Haemophilus influenzae } 11.7 \% \\
\text { Klebsiella pneumoniae } 11.7 \% \\
\text { Escherichia coli } 11.7 \% \\
\text { Flavobacterium spp } 11.7 \% \\
\text { Serratia spp } 5.8 \% \\
\text { V paravula } 5.8 \%\end{array}$ & $\begin{array}{l}\text { Small sample size; all patients required mechanical ventilation; } \\
\text { infiltrate did not have to be in dependent lobes; } 48 \% \text { of patients } \\
\text { received an antibiotic with anaerobic coverage in the } 24 \text { hours prior to } \\
\text { microbiologic sampling }\end{array}$ \\
\hline $\begin{array}{l}\text { Kadowaki et al. }{ }^{33} \\
\text { (2005) } \\
\text { Randomized prospective }\end{array}$ & $\begin{array}{l}\text { Infiltrate in the posterior } \\
\text { segments of the lower lobes }\end{array}$ & $\begin{array}{l}\text { Sputum culture isolates: } \\
\text { Klebsiella pneumoniae } 30.8 \% \\
\text { Methicillin-resistant Staphylococcus aureus (MRSA) } 14.1 \% \\
\text { MSSA } 11.5 \% \\
\text { Enterobacter } 7.7 \% \\
\text { Haemophilus influenzae } 6.4 \% \\
\text { Streptococcus pneumonia } 6.4 \% \\
\text { Serratia } 5.1 \% \\
\text { Pseudomonas aeruginosa } 5.1 \% \\
\text { Escherichia coli } 3.8 \% \\
\text { Citrobacter } 2.6 \%\end{array}$ & $\begin{array}{l}\text { Sputum cultures are less reliable than PBS; the study did not docu- } \\
\text { ment the time antibiotics were administered in relation to sputum } \\
\text { acquisition; did not specify whether sputum cultures were processed } \\
\text { for anaerobes }\end{array}$ \\
\hline
\end{tabular}


TABLE. Determining Bacterial Etiology of Aspiration Pneumonia (continued)

\begin{tabular}{|c|c|c|c|}
\hline Study & $\begin{array}{l}\text { Radiographic Criteria } \\
\text { for Diagnosis }\end{array}$ & Microbiology & Limitations \\
\hline $\begin{array}{l}\text { Shariatzadeh et al. }{ }^{2} \text { (2006) } \\
\text { Prospective }\end{array}$ & Pulmonary infiltrate & $\begin{array}{l}\text { CAAP: } \\
\text { Blood culture }{ }^{\text {b: }} \text { : } \\
\text { Staphylococcus aureus } 35.7 \% \\
\text { Streptococcus pneumoniae } 21.4 \% \\
\text { Escherichia coli } 14.3 \% \\
\text { Sputum culture: } \\
\text { Gram-negative bacilli } 45 \% \\
\text { Streptococcus pneumoniae } 20 \% \\
\text { Haemophilus influenzae } 20 \% \\
\text { Continuing care facility aspiration pneumonia: } \\
\text { Blood cultured: } \\
\text { Gram-negative bacilli } 40 \% \\
\text { Streptococcus pneumoniae } 20 \% \\
\text { Staphylococcus aureus } 20 \% \\
\text { Sputum culture } \\
\text { Pseudomonas aeruginosa } 43 \% \\
\text { Gram-negative bacilli } 29 \% \\
\text { Staphylococcus aureus } 21 \%\end{array}$ & $\begin{array}{l}\text { Infiltrate did not have to be in dependent lobes; sputum cultures are } \\
\text { less reliable than PBS; sputum and blood cultures were not performed } \\
\text { on all patients; the study did not specify when antibiotics were } \\
\text { administered in relation to the acquisition of cultures; sputum culture } \\
\text { was not processed for anaerobes }\end{array}$ \\
\hline $\begin{array}{l}\text { Lanspa et al. } .^{9}(2013) \\
\text { Retrospective }\end{array}$ & $\begin{array}{l}\text { Radiographic evidence of } \\
\text { pneumonia }\end{array}$ & $\begin{array}{l}\text { CAAP \& HCAAP: } \\
\text { Streptococcus pneumoniae } 2.5 \% \text { Enteric organisms } 2.2 \% \\
\text { MRSA } 1.9 \% \\
\text { Haemophilus sp, } 1.8 \% \\
\text { MSSA } 1.6 \% \\
\text { Pseudomonas } 1.0 \% \\
\text { Beta-hemolytic strep } 0.7 \% \\
\text { M. catarrhalis } 0.3 \% \\
\text { Neisseria sp. } 0.7 \% \\
\text { Other } 1.6 \% \\
\text { HCAAP patients had statistically significant increased rates of enteric } \\
\text { bacteria causing infection. }\end{array}$ & $\begin{array}{l}\text { Retrospective design; no clear definition of aspiration pneumonia; only } \\
7.8 \% \text { of patients had positive cultures (blood/tracheal); HCAP aspira- } \\
\text { tion patients lacked full criteria for HCAP; PBS was not used to obtain } \\
\text { culture samples; tracheal aspirate was the most common method used } \\
\text { for recovering an organism; the study did not specify when antibiotics } \\
\text { were administered in relation to the acquisition of cultures; recovery of } \\
\text { anaerobic organisms was limited to blood and pleural fluid }\end{array}$ \\
\hline $\begin{array}{l}\text { Marumo et al. }{ }^{32} \text { (2014) } \\
\text { Prospective cohort }\end{array}$ & New infiltrate & $\begin{array}{l}\text { NHCAP (all cultures }{ }^{9} \text { ): } \\
\text { Streptococcus pneumoniae 22\% } \\
\text { MSSA 10\% } \\
\text { Haemophilus influenza } 6 \% \\
\text { Escherichia coli 1.7\% } \\
\text { Pseudomonas aeruginosa 1.7\% } \\
\text { MRSA 0.9\% }\end{array}$ & $\begin{array}{l}\text { Infiltrate did not have to be in dependent lobes; NHCAP differed slight- } \\
\text { ly from standard HCAP definitions; only NHCAP patients with no risk } \\
\text { factors for MDR pathogens were evaluated; bacterial diagnosis was } \\
\text { established in only } 47 \% \text { of patients; PBS or protected bronchoalveolar } \\
\text { lavage was not used to obtain culture samples; the study did not speci- } \\
\text { fy when antibiotics were administered in relation to the acquisition of } \\
\text { cultures; anaerobic culture media was not used. }\end{array}$ \\
\hline
\end{tabular}

All isolates are expressed as a percentage of positive isolates (except for Lanspa et al. and Marumo et al.).

a $50 \%$ of patients had altered consciousness from a drug overdose, and an additional $15 \%$ aspirated because of intestinal obstruction; $72 \%$ of sterile PBS cultures were from drug overdose patients. Most patients were not older adults.

${ }^{b}$ Blood cultures were positive in only $12 \%$ of CAAP patients who had blood cultures drawn.

'Sputum cultures were positive in $44 \%$ of CAAP patients who had sputum cultures.

Blood cultures were positive in only $5 \%$ of continuing care facility patients who had blood cultures drawn.

e Sputum cultures were positive in $48 \%$ of continuing care facility patients who had sputum cultures.

${ }^{f}$ Expressed as a percentage of patients, rather than of isolates, who were carrying the pathogen.

${ }^{9}$ Expressed as a percentage of patients, rather than of isolates, who were carrying the pathogen.

clindamycin as the treatment of choice for these infections. ${ }^{24}$ Amoxicillin-clavulanic acid (IV and PO regimens), studied in the treatment of community-acquired necrotizing pneumonia/ lung abscess, shows good efficacy as well. ${ }^{25}$ This study also attempted to elucidate the underlying causative organisms in these patients. Organisms associated with CAP as well as anaerobic organisms were isolated, giving more credence to the idea of broader coverage for aspiration pneumonia.
Community-Acquired Aspiration Pneumonia/Healthcare-Associated Aspiration Pneumonia

The importance of making a diagnostic distinction between CAAP versus HCAAP is critical for management strategies. A prospective population-based study demonstrated that ICU length of stay and 30-day mortality is highest for HCAAP, followed by CAAP, and lastly for those with CAP.9 Although some studies use different nomenclature for identifying aspiration 
pneumonia patients at risk for a wider array of microorganisms, we attempt to standardize the language by using HCAAP. The literature on nonaspiration pneumonia is changing from terms such as CAP and healthcare-associated pneumonia (HCAP) to pneumonia with the risk of MDR organisms. One study proposed a new treatment algorithm for CAP based on the presence or absence of the following six risk factors: prior hospitalization of greater than or equal to two days in the preceding 90 days, immunosuppression, previous antibiotic use within the preceding 90 days, use of gastric acid-suppressive agents, tube feeding, and nonambulatory status. ${ }^{26} \mathrm{~A}$ similar approach proposed years earlier for HCAP patients found the following to be risk factors for MDR organisms: hospitalization in the past 90 days, antibiotic therapy in the past six months, poor functional status as defined by activities of daily living score, and immune suppression. ${ }^{27}$ Other factors, such as structural lung disease, that increase the risk of organisms resistant to standard antibiotic treatment regimens ${ }^{28-31}$ should be considered in aspiration pneumonia as well. Aspiration pneumonia is following a similar trajectory where the risk of MDR organisms is taking precedence over the environment of acquisition. The final nomenclature will allow the healthcare provider to understand the organisms that need to be targeted when choosing an appropriate antibiotic treatment regimen.

There is evidence supporting the premise that CAAP and nursing home patients with no risk factors for MDR organisms can be treated with standard regimens used for patients with CAP. A prospective cohort study in 2014 did not show any statistically significant differences in clinical outcomes in nursing and healthcare-associated aspiration pneumonia patients (with no risks of MDR organisms) treated with azithromycin versus ampicillin/sulbactam. However, only 36 patients were included in the azithromycin arm, and the therapeutic choices were made by the treating physician. ${ }^{32}$

A prospective study of 95 long-term care residents reported that of those patients admitted to the ICU with severe aspiration pneumonia, the causative organisms are gram-negative enteric bacilli in $49 \%$ of isolates, anaerobes in 16\%, and Staphylococcus aureus in $12 \%{ }^{22}$ This study mentioned that six of seven anaerobic pneumonia cases had inadequate anaerobic coverage yet were effectively treated; based on the organisms represented, however, the antibiotics administered did provide some coverage. ${ }^{22}$ Prevotella was one of the common anaerobic organisms that could be treated by levofloxacin or ceftriaxone/azithromycin, possibly explaining the success of azithromycin in the study quoted previously.22,32 Therefore, although anaerobic organisms still need to be considered, some may be treated by traditional CAP coverage. ${ }^{22}$

In a 2005 randomized prospective study of 100 patients aged 71 to 94 years, clindamycin was found to have clinical efficacy equivalent to ampicillin-sulbactam and panipenem in the treatment of mild-to-moderate aspiration pneumonia. ${ }^{33}$ Most patients in this study are nursing home residents, and 53\% of sputum cultures in the clindamycin arm grew gram-negative rods. In contrast to the previous study, the significance of gram-negative rod infections in this population of patients, with less severe infections, is called into question, as clindamycin has no coverage against these organisms. This premise is supported by a more recent study using azithromycin in nursing and healthcare-associated aspiration pneumonia patients, mentioned previously. ${ }^{32}$ Taken together, these three studies suggest that the severity of aspiration pneumonia may be a risk factor that needs to be taken into account when considering broad-spectrum antimicrobial coverage.

While further research is needed to validate treatment approaches, based on the current literature we propose the following:

CAAP requiring hospitalization but without any of the following-risk for PA or MDR organisms, septic shock, the need for ICU admission, or mechanical ventilation-can be treated with standard CAP therapy that covers anaerobes. ${ }^{26,32-34} \mathrm{~Pa}-$ tients with CAAP and either of the following - risk factors for MDR organisms, septic shock, need for ICU admission, or mechanical ventilation-should be considered for broader coverage with vancomycin or linezolid, antipseudomonal antibiotics, and anaerobic coverage. CAAP with specific risk for a PA infection should be considered for two antipseudomonal antibiotics (where only one can be a beta-lactam antibiotic, and one has anaerobic coverage).

Severe HCAAP without risk for MDR organisms or PA but with any of the following-septic shock, ICU admission, or mechanical ventilation-can be treated based on the 2016 Infectious Diseases Society of America guideline recommendation for hospital-acquired pneumonia, with a regimen that also provides adequate anaerobic coverage. ${ }^{35}$ If patients have HCAAP with one or more risk factors for MDR organisms, no septic shock, and no need for ICU admission or mechanical ventilation, provide coverage with a similar regimen. In contrast, HCAAP with risk factors for PA or severe HCAAP causing septic shock, requiring ICU admission, or needing mechanical ventilation, which occurs in the setting of one or more risk factors for MDR organisms, or structural lung disease, should receive two antipseudomonal antibiotics (where only one can be a beta-lactam antibiotic and one has anaerobic coverage) in addition to vancomycin or linezolid.

A recent systematic review demonstrates the paucity of studies of ideal methodologic design which complicates the ability to recommend, with confidence, one guideline-based antimicrobial regimen over another. ${ }^{36}$ Future studies may determine that despite the severity of the infection, if patients do not carry any risk for MDR pathogens or PA, they may only require CAAP coverage. When a patient presents with an acute infection, it is prudent to review previous cultures, and although it may be necessary to treat with broad-spectrum antibiotics initially, it is always important to narrow the spectrum based on reliable culture results. If future studies support the results of many studies cited in this article, we may be using fewer antibiotics with narrower spectrums in the near future.

\section{Prevention}

Although the healthcare system has practices in place to prevent aspiration pneumonia, the evidence supporting them 
are either inconclusive or not of ideal methodological design. Two systematic reviews failed to show statistically significant decreases in rates of aspiration pneumonia or mortality using the standard of care positioning strategies or thickened fluids in patients with chronic dysphagia. ${ }^{37,38}$ One study showed a decreased incidence of all pneumonia in dysphasic patients with dementia or Parkinson disease when a chin-down posture (with thin liquids) or thickened fluids in a head-neutral position was used. The study, however, has significant limitations, including a lack of a "no treatment" group for comparison, which did not allow investigators to conclude that the decreased incidence was from their interventions. ${ }^{39}$

There are preventive strategies that show a decreased risk of aspiration pneumonia. Poor oral hygiene seems to be a modifiable risk factor to establish better control of oral flora and decrease aspiration pneumonia. A systematic review of five studies, evaluating the effects of oral healthcare on the incidence of aspiration pneumonia in frail older people, found that tooth brushing after each meal along with cleaning dentures once a day and professional oral healthcare once a week decreases febrile days, pneumonia, and dying from pneumonia. ${ }^{40} \mathrm{~A}$ two-year historical cohort study using aromatherapy with black pepper oil, followed by application of capsaicin troches, and finally menthol gel, as the first meal, leads to a decreased incidence of pneumonia and febrile days in older adults with dysphagia. ${ }^{41}$ Well-designed validation studies may establish these practices as the new standard of care for preventing pneumonia in patients with dysphagia.

\section{Feeding Tubes}

Multiple studies show that in older adults with advanced dementia there is no survival benefit from percutaneous endoscopic gastrostomy (PEG) tube placement ${ }^{42-44}$ and more recent systematic reviews also conclude that there is currently no evidence to support the use of PEG tubes in this specific population. ${ }^{45,46}$ In February 2013, as part of the American Board of Internal Medicine Foundation Choosing Wisely ${ }^{\circledR}$ campaign, the American Geriatrics Society advised providers not to recommend percutaneous feeding tubes in patients with advanced dementia, rather, "offer assisted oral feeding." ${ }^{47}$ It is worth noting, however, that none of the studies reviewed were of ideal methodological design, so opinions may change with future studies.

A more recent study compared liquid feeds versus semisolid feeds in patients with PEG tubes. The study shows a $22.2 \%$ incidence of aspiration pneumonia in the liquid feed group, which is comparable to prior studies, but the incidence of aspiration pneumonia is only $2.2 \%$ in the semisolid feed group $(P<.005) .{ }^{48} \mathrm{~A}$ benefit of this size warrants future studies for validation.

\section{CONCLUSION}

Aspiration pneumonia leads to increased mortality when compared with CAP and HCAP. ${ }^{2}$ Until future studies validate or refute the current understanding surrounding its management, the following should provide some guidance: aspiration pneu- monia should be suspected in any individual with risk factors of aspiration who presents with typical or atypical symptoms of pneumonia. Confirmation of the diagnosis requires an image representative of pneumonia in the typical dependent lung segment on chest X-ray, lung ultrasound, or noncontrast CT scan of the chest. Treatment of aspiration pneumonia should take into account the site of acquisition, severity of illness, and risk for MDR organisms as the causative organisms may include Streptococcus pneumoniae, Haemophilus influenzae, Staphylococcus aureus, and gram-negative rods, in addition to the traditional organisms classically thought to cause aspiration pneumonia-anaerobes.

Disclosures: The authors have nothing to disclose.

\section{References}

1. Wu CP, Chen YW, Wang MJ, Pinelis E. National trends in admission for aspiration pneumonia in the United States, 2002-2012. Ann Am Thorac Soc. 2017;14(6):874-879. doi: 10.1513/AnnalsATS.201611-867OC.

2. Reza Shariatzadeh $M$, Huang JQ, Marrie TJ. Differences in the features of aspiration pneumonia according to site of acquisition: community or continuing care facility. J Am Geriatr Soc. 2006;54(2):296-302. doi: 10.1111/j.15325415.2005.00608.x.

3. Bartlett JG, Gorbach SL. The triple threat of aspiration pneumonia. Chest. 1975;68(4):560-566. doi: 10.1378/chest.68.4.560.

4. Huxley EJ, Viroslav J, Gray WR, Pierce AK. Pharyngeal aspiration in normal adults and patients with depressed consciousness. Am J Med. 1978;64(4):564568. doi: 10.1016/0002-9343(78)90574-0.

5. Marik PE. Aspiration pneumonitis and aspiration pneumonia. N Engl J Med. 2001;344(9):665-671. doi: 10.1056/NEJM200103013440908.

6. Raghavendran K, Nemzek J, Napolitano LM, Knight PR. Aspiration-induced lung injury. Crit Care Med. 2011;39(4):818-826. doi: 10.1097/CCM.0b013e31820a856b.

7. Riquelme R, Torres $A$, el-Ebiary $M$, et al. Community-acquired pneumonia in the elderly. Clinical and nutritional aspects. Am J Respir Crit Care Med. 1997;156(6):1908-1914. doi: 10.1164/ajrccm.156.6.9702005.

8. Venkatesan P, Gladman J, Macfarlane JT, et al. A hospital study of community acquired pneumonia in the elderly. Thorax. 1990;45(4):254-258. doi: 10.1136/ thx.45.4.254.

9. Lanspa MJ, Jones BE, Brown SM, Dean NC. Mortality, morbidity, and disease severity of patients with aspiration pneumonia. J Hosp Med. 2013;8(2):83-90. doi: 10.1002/jhm.1996.

10. Fernández-Sabé N, Carratalà J, Rosón B, et al. Community-acquired pneumonia in very elderly patients: causative organisms, clinical characteristics, and outcomes. Medicine (Baltimore). 2003;82(3):159-169. doi: 10.1097/01. md.0000076005.64510.87

11. Mehr DR, Binder EF, Kruse RL, et al. Clinical findings associated with radiographic pneumonia in nursing home residents. J Fam Pract. 2001;50(11):931937.

12. Bentley DW, Bradley S, High K, et al. Practice guideline for evaluation of fever and infection in long-term care facilities. Clin Infect Dis. 2000;31(3):640653. doi: $10.1086 / 314013$.

13. van der Maarel-Wierink CD, Vanobbergen JN, Bronkhorst EM, Schols JM, de Baat C. Risk factors for aspiration pneumonia in frail older people: a systematic literature review. J Am Med Dir Assoc. 2011;12(5):344-354. doi: 10.1016/j. jamda.2010.12.099.

14. Hollaar V, van der Maarel-Wierink C, van der Putten GJ, et al. Defining characteristics and risk indicators for diagnosing nursing home-acquired pneumonia and aspiration pneumonia in nursing home residents, using the electronically-modified Delphi Method. BMC Geriatr. 2016;16:60. doi: 10.1186/ s12877-016-0231-4.

15. Esayag Y, Nikitin I, Bar-Ziv J, et al. Diagnostic value of chest radiographs in bedridden patients suspected of having pneumonia. Am J Med. 2010;123(1):88.e1-88.e5. doi: 10.1016/j.amjmed.2009.09.012.

16. Claessens $Y E$, Debray MP, Tubach F, et al. Early chest computed tomography scan to assist diagnosis and guide treatment decision for suspected community-acquired pneumonia. Am J Respir Crit Care Med. 2015;192(8):974-982. doi: 10.1164/rccm.201501-0017OC. 
17. Liu XL, Lian R, Tao YK, Gu CD, Zhang GQ. Lung ultrasonography: an effective way to diagnose community-acquired pneumonia. Emerg Med J. 2015;32(6):433-438. doi: 10.1136/emermed-2013-203039.

18. Bourcier JE, Paquet J, Seinger M, et al. Performance comparison of lung ultrasound and chest $x$-ray for the diagnosis of pneumonia in the ED. Am J Emerg Med. 2014;32(2):115-118. doi: 10.1016/j.ajem.2013.10.003.

19. Chavez MA, Shams N, Ellington LE, et al. Lung ultrasound for the diagnosis of pneumonia in adults: a systematic review and meta-analysis. Respir Res. 2014;15:50. doi: 10.1186/1465-9921-15-50.

20. Syrjälä H, Broas M, Suramo I, Ojala A, Lähde S. High-resolution computed tomography for the diagnosis of community-acquired pneumonia. Clin Infect Dis. 1998;27(2):358-363. doi: 10.1086/514675.

21. Hayden GE, Wrenn KW. Chest radiograph vs. computed tomography scan in the evaluation for pneumonia. J Emerg Med. 2009;36(3):266-270. doi: 10.1016/j.jemermed.2007.11.042.

22. El-Solh AA, Pietrantoni C, Bhat A, et al. Microbiology of severe aspiration pneumonia in institutionalized elderly. Am J Respir Crit Care Med. 2003;167(12):1650-1654. doi: 10.1164/rccm.200212-15430C

23. Levison ME, Mangura CT, Lorber $B$, et al. Clindamycin compared with penicillin for the treatment of anaerobic lung abscess. Ann Intern Med. 1983:98(4):466-471. doi: 10.7326/0003-4819-98-4-466

24. Gudiol F, Manresa F, Pallares R, et al. Clindamycin vs penicillin for anaerobic lung infections. High rate of penicillin failures associated with penicillin-resistant Bacteroides melaninogenicus. Arch Intern Med. 1990;150(12):2525-2529. doi: 10.1001/archinte.150.12.2525.

25. Germaud P, Poirier J, Jacqueme P, et al. Monotherapy using amoxicillin/ clavulanic acid as treatment of first choice in community-acquired lung abscess. Apropos of 57 cases. Rev Pneumol Clin. 1993;49(3):137-141.

26. Shindo $Y$, Ito R, Kobayashi D, et al. Risk factors for drug-resistant pathogens in community-acquired and healthcare-associated pneumonia. Am J Respir Crit Care Med. 2013;188(8):985-995. doi: 10.1164/rccm.201301-00790C.

27. Brito $V$, Niederman MS. Healthcare-associated pneumonia is a heterogeneous disease, and all patients do not need the same broad-spectrum antibiotic therapy as complex nosocomial pneumonia. Curr Opin Infect Dis. 2009;22(3):316-325. doi: 10.1097/QCO.0b013e328329fa4e

28. Restrepo MI, Babu BL, Reyes LF, et al. Burden and risk factors for Pseudomonas aeruginosa community-acquired pneumonia: a multinational point prevalence study of hospitalised patients. Eur Respir J. 2018;52(2). doi: 10.1183/13993003.01190-2017.

29. Mandell LA, Wunderink RG, Anzueto A, et al. Infectious Diseases Society of America/American Thoracic Society consensus guidelines on the management of community-acquired pneumonia in adults. Clin Infect Dis. 2007;44 Supplement 2:S27-S72. doi: 10.1086/511159.

30. Cillóniz C, Gabarrús A, Ferrer M, et al. Community-acquired pneumonia due to multidrug- and non-multidrug-resistant Pseudomonas aeruginosa. Chest. 2016;150(2):415-425. doi: 10.1016/j.chest.2016.03.042

31. Prina E, Ranzani OT, Polverino E, et al. Risk factors associated with potentially antibiotic-resistant pathogens in community-acquired pneumonia. Ann Am Thorac Soc. 2015;12(2):153-160. doi: 10.1513/AnnalsATS.201407-305OC.

32. Marumo S, Teranishi T, Higami $Y$, et al. Effectiveness of azithromycin in aspiration pneumonia: a prospective observational study. BMC Infect Dis. 2014;14:685. doi: 10.1186/s12879-014-0685-y.

33. Kadowaki M, Demura Y, Mizuno S, et al. Reappraisal of clindamycin IV monotherapy for treatment of mild-to-moderate aspiration pneumonia in elderly patients. Chest. 2005:127(4):1276-1282. doi: 10.1378/chest.127.4.1276.

34. Maruyama T, Fujisawa T, Okuno M, et al. A new strategy for healthcare-associated pneumonia: a 2-year prospective multicenter cohort study using risk factors for multidrug-resistant pathogens to select initial empiric therapy.
Clin Infect Dis. 2013;57(10):1373-1383. doi: 10.1093/cid/cit571.

35. Kalil AC, Metersky ML, Klompas M, et al. Executive Summary: management of adults with hospital-acquired and ventilator-associated pneumonia: 2016 clinical practice guidelines by the Infectious Diseases Society of America and the American Thoracic Society. Clin Infect Dis. 2016;63(5):575-582. doi: 10.1093/cid/ciw504

36. Bowerman TJ, Zhang J, Waite LM. Antibacterial treatment of aspiration pneumonia in older people: a systematic review. Clin Interv Aging. 2018;13:2201-2213. doi: 10.2147/CIA.S183344.

37. Loeb MB, Becker M, Eady A, Walker-Dilks C. Interventions to prevent aspiration pneumonia in older adults: a systematic review. J Am Geriatr Soc. 2003;51(7):1018-1022. doi: 10.1046/j.1365-2389.2003.51318.x.

38. Andersen UT, Beck AM, Kjaersgaard A, Hansen T, Poulsen I. Systematic review and evidence based recommendations on texture modified foods and thickened fluids for adults (\&\#x2265;18 years) with oropharyngeal dysphagia. Clin Nutr ESPEN. 2013;8(4):e127-e134

39. Robbins J, Gensler G, Hind J, et al. Comparison of 2 interventions for liquid aspiration on pneumonia incidence: a randomized trial. Ann Intern Med. 2008;148(7):509-518. doi: 10.7326/0003-4819-148-7-200804010-00007.

40. van der Maarel-Wierink CD, Vanobbergen JN, Bronkhorst EM, Schols JM, de Baat $C$. Oral health care and aspiration pneumonia in frail older people: a systematic literature review. Gerodontology. 2013;30(1):3-9. doi: 10.1111/j.1741-2358.2012.00637.x

41. Ebihara T, Ebihara S, Yamazaki M, et al. Intensive stepwise method for oral intake using a combination of transient receptor potential stimulation and olfactory stimulation inhibits the incidence of pneumonia in dysphagic older adults. J Am Geriatr Soc. 2010;58(1):196-198. doi: 10.1111/j.15325415.2009.02648.x

42. Sanders DS, Carter MJ, D'Silva J, et al. Survival analysis in percutaneous endoscopic gastrostomy feeding: a worse outcome in patients with dementia. Am J Gastroenterol. 2000;95(6):1472-1475. doi: 10.1111/j.15720241.2000.02079.x

43. Murphy LM, Lipman TO. Percutaneous endoscopic gastrostomy does not prolong survival in patients with dementia. Arch Intern Med. 2003;163(11):1351-1353. doi: 10.1001/archinte.163.11.1351.

44. Rimon E, Kagansky N, Levy S. Percutaneous endoscopic gastrostomy; evidence of different prognosis in various patient subgroups. Age Ageing. 2005;34(4):353-357. doi: 10.1093/ageing/afi085

45. Candy B, Sampson EL, Jones L. Enteral tube feeding in older people with advanced dementia: findings from a Cochrane systematic review. Int J Palliat Nurs. 2009;15(8):396-404. doi: 10.12968/ijpn.2009.15.8.43799.

46. Goldberg LS, Altman KW. The role of gastrostomy tube placement in advanced dementia with dysphagia: a critical review. Clin Interv Aging. 2014;9:1733-1739. doi: 10.2147/CIA.S53153.

47. Workgroup AGSCW. American Geriatrics Society identifies five things that healthcare providers and patients should question. J Am Geriatr Soc. 2013;61(4):622-631. doi: 10.1111/jgs.12226

48. Toh Yoon EW, Yoneda K, Nishihara K. Semi-solid feeds may reduce the risk of aspiration pneumonia and shorten postoperative length of stay after percutaneous endoscopic gastrostomy (PEG). Endosc Int Open. 2016:4(12):E1247-E1251. doi: 10.1055/s-0042-117218.

49. Mier L, Dreyfuss $D$, Darchy $B$, et al. Is penicillin- $G$ an adequate initial treatment for aspiration pneumonia? A prospective evaluation using a protected specimen brush and quantitative cultures. Intens Care Med. 1993;19(5):279284. doi: 10.1007/BF01690548.

50. Marik PE, Careau P. The role of anaerobes in patients with ventilator-associated pneumonia and aspiration pneumonia: a prospective study. Chest. 1999;115(1):178-183. doi: 10.1378/chest.115.1.178. 